\title{
ENSINANDO MATEMÁTICA ATRAVÉS DE ATIVIDADES LÚDICAS
}

\author{
FISCHER, Marlise - Licenciada em Matemática/CAJ/UFG \\ GOULART, Grace Kelly Souza Carmo - Licenciada em Matemática/CAJ/UFG \\ gkscg_83@hotmail.com \\ GOULART, Claudiney - Mestre em Matemática /UNB - Docente CCM/CAJ/UFG \\ claudineygoulart@hotmail.com
}

RESUMO: O presente artigo descreve o desenvolvimento de uma Proposta Pedagógica que tratou de atividades lúdicas no ensino da matemática. Ela foi realizada em uma turma de $8^{a}$ série do ensino fundamental, na escola Instituto Samuel Graham, no ano de 2004. Com o tema "Ensinando Matemática Através de Atividades Lúdicas", foram desenvolvidos os seguintes conteúdos de geometria: áreas de figuras planas, perímetro e área do círculo e volume de sólidos geométricos. A partir destes conteúdos, procuramos desenvolver jogos pedagógicos, por meio de malhas quadriculadas (papel milimetrado e geoplano), recortes de cartolina e material dourado, e jogos de treinamento, isto porque Araújo (2000) afirma que essas atividades geram prazer, equilíbrio emocional, levam o aluno à autonomia sobre seus atos e pensamentos e contribui para o desenvolvimento social. Além disso, tornam as aulas dinâmicas e prazerosas facilitando assim o processo de ensino-aprendizagem do aluno. Nossa proposta foi norteada pelos seguintes objetivos: levar o aluno a fixar conceitos já ministrados, fazer com que o aluno deixe de ser um memorizador de fórmulas e através da dedução possa aprendê-las e entendê-las, para então motivar os alunos a uma nova aprendizagem. E para que esses objetivos fossem alcançados, procuramos buscar, através de nossa prática pedagógica, uma nova sala de aula onde valoriza-se o aluno, sua realidade, suas inteligências múltiplas, suas concepções prévias, atendendo a um novo cenário educacional, recriando novas formas de aprender.

Palavras-chave: atividades lúdicas - ensino de matemática - jogos.

\begin{abstract}
This article describes the development of a pedagogic proposal that dealt with gamelike activities in the mathematics teaching. It was carried out in an $8^{\text {th }}$ grade class of junior high school (secondary school) in the school Instituto Samuel Graham, in 2004. With the theme "teaching mathematics through playful activities", the following content of geometry was developed: areas of that shapes, perimeter and area of circles and volume of geometric solids. Starting from this content, we tried to develop pedagogic games, through squared meshes/paper (milimetric paper and geoplane), slips of card and gold material, as well as games of training. We used this procedures accoding to Araujo (2000), who affirms that these activities produce pleasure, emotional balance, lead the student to autonomy about his/her acts and thoughts and contribute to social development. Besides, these activities make the classes dynamic and pleasurable, facilitating the process of leading the student to reinforce content that has already been given, to make the student stop memorizing formulas and through the deduction he/she to learn and understand them, in order to motivate the students to a new learning process. To achieve these goals, we tried, through our pedagogic practice, to look for a new class where the student and his/her reality are valued, as well as his/her multiple intelligences, previous conceptions, attending a new educational setting, recreating new ways of learning.
\end{abstract}

Key-words: gamelike activities - mathematics teaching- - games.

Introdução

Este artigo refere-se a uma proposta pedagógica elaborada e desenvolvida durante o $4^{\circ}$ ano do Curso de Graduação em Matemática da Universidade Federal de Goiás - Campus Avançado de Jataí, onde utilizamos atividades lúdicas no ensino da Matemática. A proposta abrange a utilização de atividades lúdicas, em específico jogos pedagógicos e jogos de treinamento, com o intuito de facilitar o processo de ensino-aprendizagem, levando o aluno a 
se apropriar do conhecimento, vivenciando e experimentando, ou seja, passando a ser elemento ativo do seu processo de aprendizagem.

Sabe-se que no ensino atual faz-se necessário a introdução de novas tecnologias que levem o aluno a ser sujeito da aprendizagem, respeitando seu contexto, considerando suas motivações, curiosidade e desejo de realizar atividades em grupo. Neste sentido Araújo (2000) afirma que as atividades lúdicas têm seu espaço assegurado, despertando no aluno o interesse, criando um ambiente de aprendizagem favorável.

De acordo com Brasil (1998), a Matemática dá a sua contribuição à formação do cidadão, pois desenvolve metodologias que enfatizam a construção de estratégias, a comprovação e justificativa de resultados, a criatividade, a iniciativa pessoal, o trabalho coletivo e a autonomia advinda da confiança na própria capacidade para enfrentar desafios.

Mas sabe-se que a realidade não é bem essa. O que se vê nas escolas são dificuldades tanto por parte dos professores quanto dos alunos. Os alunos não conseguem aprender a matemática que lhes é ensinada na escola, muitas vezes são reprovados nesta disciplina, ou então, mesmo que aprovados, sentem dificuldades em utilizar o conhecimento que os professores acreditam que eles tenham adquirido.

Por outro lado, o professor, consciente de que não consegue alcançar resultados satisfatórios junto aos seus alunos, tem dificuldades de, por si só, repensar seu fazer pedagógico.

Além disso, Alves (2001) considera que com a prática pedagógica tradicional, estática, onde o trabalho é centralizado na figura do professor, o aluno torna-se passivo, apenas ouve e obedece.

Segundo Araújo, através das atividades lúdicas, é possível tornar as aulas dinâmicas e prazerosas facilitando assim, o processo de ensino-aprendizagem e levando o aluno a se apropriar do conhecimento, vivenciando, experimentando e se tornando uma pessoa autônoma para poder aplicar seus conhecimentos na vida.

A autora Borin (2002) defende a atividade lúdica enfatizando o jogo. Para ela, nas aulas com jogos, os alunos passam a ser elementos ativos do seu processo de aprendizagem, vivenciando a construção do saber e deixando de ser um mero ouvinte passivo.

Ante essas reflexões, procuramos aliar atividades lúdicas ao ensino da matemática buscando uma mudança de comportamento por parte dos alunos como auto-estima, interesse, motivação, criatividade, autonomia, alegria, prazer, entre outros.

Para isso, traçamos os seguintes objetivos: 
- Levar o aluno a fixar conceitos já ministrados (jogo de treinamento);

- Fazer com que o aluno deixe de ser um memorizador de fórmulas e, através da dedução (com geoplano, material dourado, recortes de cartolina), possa aprendê-las e entendê-las (jogo pedagógico);

- E assim, motivar os alunos a uma nova aprendizagem.

Seguindo esta linha de pensamento e com o intuito de tornar as aulas de matemática interessantes e prazerosas, e ainda, levar o aluno a construir o conhecimento, proporcionando uma aprendizagem significativa é que optamos pelo ensino através de atividades lúdicas.

Etapas do desenvolvimento da proposta pedagógica

A proposta pedagógica que elaboramos foi aplicada na escola Instituto Samuel Graham em uma turma de $8^{\mathrm{a}}$ série do Ensino Fundamental na cidade de Jataí-GO, no ano de 2004. O desenvolvimento da mesma é parte de um estágio supervisionado que se divide em três etapas: observação do ambiente escolar, elaboração e aplicação da proposta pedagógica.

No período de observação, que teve início no mês de março, nosso intuito era coletar dados acerca do comportamento da turma e da postura da professora titular em sala de aula, para, posteriormente, nos auxiliar na elaboração de nossa proposta pedagógica. Além disso, neste período fizemos uma análise da escola, abordando sua estrutura física e administrativa.

Libâneo (2001) justifica a importância desta abordagem, pois para ele a organização da escola incide diretamente na eficácia do processo de ensino e aprendizagem à medida que garante as condições de funcionamento da escola e uma ação unificada da equipe escolar.

Ainda nesta etapa do trabalho foi feita uma pesquisa bibliográfica, em que buscamos orientações em Brasil (1998) e em obras dos autores Alves (2001), Araújo (2000) e Borin (2002) para nos auxiliar na elaboração e no desenvolvimento de nossa proposta pedagógica.

No mês de maio, teve início a elaboração da proposta, quando organizamos todos os dados coletados e verificamos que a maioria dos alunos era desmotivado, desinteressado, disperso, agitado, com dificuldade de aprendizagem, poucos questionavam suas dúvidas quanto à matéria estudada. Sabendo dessas dificuldades, e levando em consideração as 
palavras de Alves, a qual afirma que através do jogo o aluno pode fixar conceitos, desenvolver o senso crítico e criativo, propiciar a solidariedade entre colegas, entre outros, sentimos a necessidade de uma proposta que entusiasmasse os alunos, optando por atividades lúdicas para o ensino da matemática.

Já a aplicação da proposta deu-se durante todo o mês de agosto, a qual será abordada mais adiante, quando faremos a discussão dos resultados obtidos e as conclusões a que chegamos sobre o uso de atividades lúdicas como apoio no processo de ensinoaprendizagem.

\section{Referencial Teórico}

Devido as grandes mudanças na sociedade, cabe à escola criar sujeitos autônomos, críticos, capazes de trabalhar em grupo e de enfrentar e se adaptar a novas situações. Tornase, assim necessário a introdução de novas tecnologias que levem o aluno a ser sujeito da aprendizagem, respeitando o seu contexto, considerando suas motivações (aspectos recreativos e lúdicos), curiosidade e desejo de realizar atividades em grupo.

Dentro desta ótica, Araújo (2000) afirma que as atividades lúdicas têm seu espaço assegurado, despertando no aluno o interesse, criando um ambiente de aprendizagem favorável. E ainda define atividades lúdicas como sendo:

“... atividades que geram prazer, equilibrio emocional, levam o aluno a autonomia sobre seus atos e pensamentos e contribuem para o desenvolvimento social" (Araújo, 2000).

Dentro do lúdico, podemos citar o jogo que é uma atividade prazerosa, pois além de ser um desafio, cria condições agradáveis e favoráveis à aprendizagem, onde o indivíduo é motivado a trabalhar e pensar tendo por base o material concreto, descobrindo, reinventando e não só recebendo informações.

Segundo Brasil (1998), os jogos contribuem na formação de atitudes necessárias para a aprendizagem de matemática, dentre elas, enfrentar desafios, lançar-se à busca de soluções, desenvolvimento da crítica, da intuição, etc. Para Alves (2001),

"O jogo, pode fixar conceitos, motivar os alunos, propiciar a solidariedade entre colegas, desenvolver o senso crítico e criativo, estimular o raciocínio, descobrir novos conceitos". 
Borin (2002) justifica a introdução de jogos nas aulas de matemática como a possibilidade de diminuir os bloqueios apresentados pelos alunos que temem tal disciplina. Segundo a autora, no jogo é impossível uma atitude passiva, pois a motivação é grande.

A educação por meio de atividades lúdicas estimula as relações cognitivas, afetivas, sociais, propiciam atitudes de crítica e de criação nos alunos, isso é relatado tanto nas idéias de Piaget quanto de Vygotsky, citados por Alves.

Piaget defende o uso de jogos na educação, criticando a escola tradicional que tem como objetivo acomodar os alunos a conhecimentos tradicionais, que se opõem às suas idéias de formar indivíduos inventivos, críticos e criadores.

Vygotsky afirma que é através do jogo que o aluno aprende a agir, sua curiosidade é estimulada, adquire iniciativa e autoconfiança, proporciona o desenvolvimento da linguagem, do pensamento, e da concentração.

Torna-se evidente que a participação em jogos contribui para a formação de atitudes sociais: respeito mútuo, cooperação, obediência às regras, senso de responsabilidade, senso de justiça, iniciativa pessoal e grupal.

O jogo é o vínculo que une a vontade e o prazer durante a realização de uma atividade. Assim, o ensino através de atividades lúdicas cria um ambiente gratificante e atraente, que serve como estímulo para o desenvolvimento integral do aluno.

\section{O desenvolvimento da proposta pedagógica}

Como já foi dito anteriormente a proposta foi aplicada na escola Instituto Samuel Graham em uma turma de $8^{\text {a }}$ série do Ensino Fundamental na cidade de Jataí-GO. A mesma foi desenvolvida levando em consideração os seguintes conteúdos de geometria: área de figuras planas, perímetro (ou comprimento) da circunferência e volume de sólidos geométricos.

De acordo com Brasil (1998), estes conteúdos devem apoiar-se em procedimentos que favoreçam a compreensão das noções envolvidas, como por exemplo, a obtenção de áreas através de composição e decomposição de figuras cuja área eles já sabem calcular, por meio de procedimentos de contagem (papel quadriculado), entre outros.

Levando em consideração Brasil, os procedimentos que nortearam nossa proposta pedagógica foram: 
a) Introdução do conceito de área por meio de malhas quadriculadas (área do quadrado, retângulo, paralelogramo, triângulo, trapézio e losango);

- Dedução, por meio de papel quadriculado, das fórmulas para o cálculo da área do quadrado e do retângulo;

- Dedução, através do geoplano, das fórmulas para o cálculo da área do paralelogramo, triângulo, trapézio e losango.

b) Introdução do conceito de volume de blocos por meio de material dourado;

c) Introdução do conceito de perímetro (ou comprimento) da circunferência a partir de um valor aproximado para o número $\pi$;

d) Introdução do conceito de área do círculo por meio de recortes de cartolina;

e) Aplicação de jogos para fixar os conceitos do conteúdo estudado: jogo da memória e jogo da corrida ${ }^{1}$.

A partir de então, desenvolvemos estes procedimentos, baseados principalmente em atividades lúdicas, a saber, ensino através de geoplano (malhas quadriculadas), material dourado, recortes de cartolina ${ }^{2}$, para a dedução de fórmulas, e jogos de treinamento ${ }^{3}$ para fixar os conceitos estudados, ambos com o intuito de motivar os alunos a uma nova aprendizagem.

Pensando em tornar as aulas divertidas e interessantes, tomamos o cuidado de: não tornar o jogo algo obrigatório; utilizar atividades que envolvam dois ou mais alunos, para que ocorra uma interação social; estabelecer regras, que podem ou não ser modificadas no decorrer de uma rodada; e estudar o jogo antes de aplicá-lo.

Acreditamos que os jogos contribuem no processo ensinar-aprender, sendo que através do geoplano, material dourado e recortes o aluno pode observar, classificar, manipular, propor e comparar hipóteses, chegar a conclusões e não apenas receber informações, e no jogo de treinamento, além de fixar conceitos, motiva, propicia a solidariedade entre colegas, estimula o raciocínio, entre outros.

Em nossa primeira aula trabalhamos com "Áreas de figuras geométricas planas" em específico do quadrado e do retângulo. Inicialmente apresentamos exemplos de malhas quadriculadas aos alunos, entre elas: papel quadriculado e geoplano. Após esse contato inicial introduzimos a unidade padrão de área, representada por um quadradinho. A partir de então as

\footnotetext{
${ }^{1}$ Estes jogos foram elaborados a partir de jogos já conhecidos sendo que neste caso adaptamos para o conteúdo em questão.

${ }^{2}$ Designamos geoplano (malhas quadriculadas), material dourado e recortes de cartolina como sendo jogo pedagógico.

${ }^{3}$ Estes jogos são idealizados para auxiliar a memorização ou fixação de conceitos, fórmulas e técnicas ligadas a alguns tópicos do conteúdo (Borin, 2002).
} 
áreas das figuras seriam obtidas através da contagem de "quadradinhos". Em seguida definimos área de uma figura plana.

Dos exemplos para obter a área por contagem de quadradinhos, um deles envolvia arcos de circunferência e para chegar a um número exato de quadradinhos era necessário transladar algumas de suas partes. Isso foi mostrado aos alunos através de recortes de cartolina que, segundo Araújo (2000), durante esta atividade o aluno pode observar, classificar, manipular, entre outros.

Em seguida partimos para a "dedução" das áreas do quadrado e do retângulo, também por contagem de quadradinhos. Já para a dedução das fórmulas das áreas do paralelogramo, triângulo, trapézio e losango, partimos das áreas já conhecidas para eles: quadrado e retângulo, sempre procurando ressaltar que a figura poderia ser transformada em outra de área conhecida.

Para volume de blocos e cubos, utilizamos a mesma técnica das aulas sobre área, com o uso de material dourado.

Ao trabalharmos com perímetro (ou comprimento) da circunferência iniciamos questionando os alunos acerca dos termos circunferência, raio e diâmetro, incentivando com ilustrações no quadro, como no diálogo entre Leonardo (L) e a Professora estagiária (P):

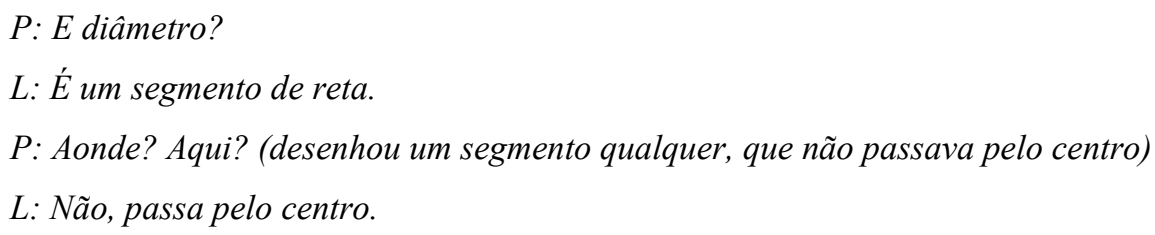

$\mathrm{Na}$ mesma aula realizamos uma experiência com objetos circulares, nesta os alunos deveriam medir o contorno e o diâmetro dos objetos e estabelecer uma relação entre estes. A partir desta relação chega-se à fórmula do perímetro (ou comprimento) da circunferência.

Iniciamos a aula sobre área do círculo, mostrando aos alunos um círculo dividido em 16 partes iguais (fatias), sendo 8 fatias verde e 8 fatias laranja intercaladas e outro círculo igual ao primeiro, porém com suas fatias recortadas, que foram encaixadas convenientemente ${ }^{5}$ (conforme figura a seguir) de forma a compor uma figura, da qual já se conhecia a área (neste caso aproximadamente um paralelogramo). Com a figura já montada, perguntamos aos alunos se a mesma lembrava alguma figura que eles conheciam. Alguns responderam que era um

\footnotetext{
${ }^{4}$ As aspas significam que não foi bem uma dedução e sim uma forma de mostrar a área para que os alunos entendessem melhor.

${ }^{5}$ Todas as fatias verdes embaixo e as laranjas encaixadas em sentido contrário.
} 
retângulo, mas depois de explicarmos as propriedades do retângulo, lembraram que se tratava de um paralelogramo.
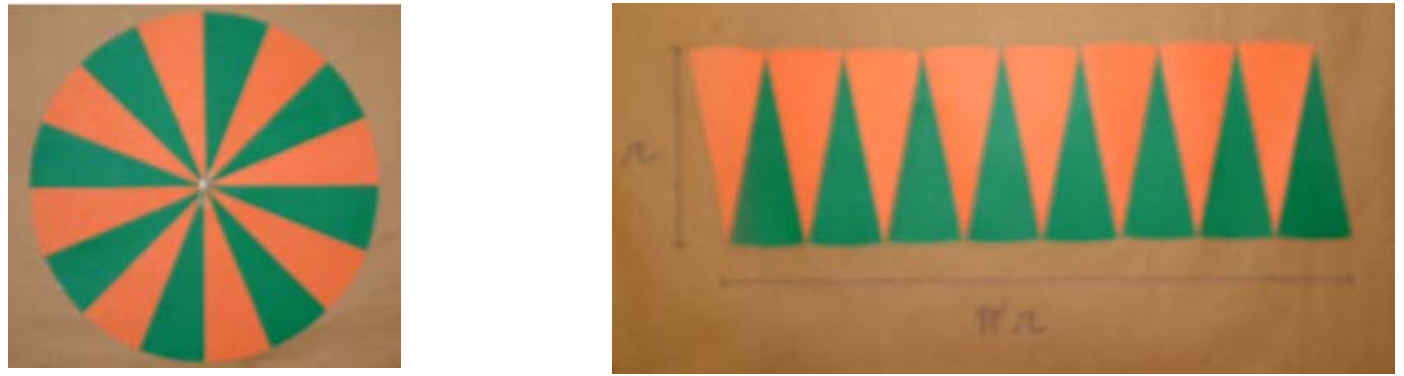

Figura 01 - Recorte para a demonstração da área do círculo

Já sabendo que a figura era um paralelogramo (aproximadamente) que tem como área base $\mathrm{x}$ altura, bastava saber qual a base e a altura, em função das medidas do círculo, chegando à fórmula da área do círculo.

Nas aulas de resolução e correção de exercícios, auxiliávamos os alunos deixando prevalecer sempre as idéias dos mesmos. Tivemos uma situação em que era necessário decompor as figuras para então calcular a área. A aluna Patrícia Bellé (PB) usou esta técnica de uma maneira bem simples conforme descrito abaixo:

Com relação à figura c, P explica que tem várias maneiras de resolver.

$P B$ vai no quadro mostrar como fez.

PB: Corta aqui, põe aqui, corta aqui, põe aqui, junta os dois e põe aqui. (mostra na figura que estava desenhada no quadro)

PB: Que é a área do retângulo de baixo.

$P$ : Vocês entenderam como PB fez?

P explica aos alunos.

$P$ resolve, calculando a área do retângulo formado.

P: Alguém não entendeu desta forma? Ou alguém fez de forma diferente?

A maioria dos alunos entendeu.

A figura a seguir ilustra o desenvolvimento que a aluna realizou no quadro:
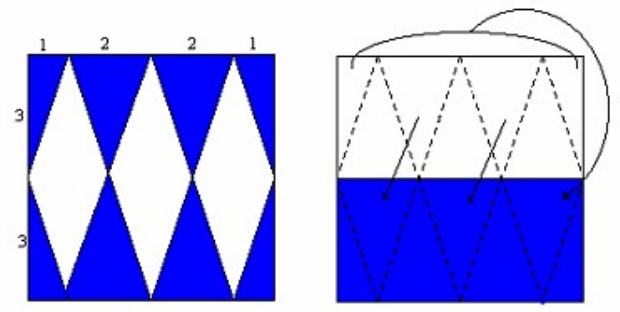

Figura 02 - Exercício Resolvido por Patrícia 
Com isto, pudemos perceber que a aluna usou o seu conhecimento de recortes e geoplano (utilizados em demonstrações de áreas), transformando a figura inicial em um retângulo, cuja área é fácil de calcular.

Sempre após as listas de exercícios eram aplicados os jogos de treinamento, a saber, Jogo da Memória e Jogo da Corrida com o intuito de ajudar ainda mais a fixar o conteúdo. As contribuições destes jogos no processo de ensino-aprendizagem serão destacadas na seção a seguir.

\section{Contribuições dos jogos}

No mundo atual as mudanças na educação precisam acontecer e apontam para um ensino aliado à realidade do tempo/espaço, ou seja, um ensino que possibilite a ação e a interação entre os alunos e professores, através de aulas que estimulem a atividade criativa, a iniciativa e o raciocínio, e também estimule o aluno a compartilhar o trabalho com os colegas através de questões problematizadas e vivências práticas. O jogo é uma dessas atividades, o qual desperta a curiosidade e a vontade de aprender, assim a aprendizagem ocorre num contexto de desafio, de espírito lúdico (Araújo, 2000).

Como já referido em nossa proposta pedagógica, utilizamos jogos de treinamento, com o intuito de fixar os conceitos estudados. Foram realizados dois jogos (memória e corrida), ambos por nós confeccionados e adaptados a partir de jogos conhecidos.

Para a realização destes, tivemos alguns cuidados como o estudo do jogo, com a finalidade de observar as possíveis dúvidas e dificuldades que os alunos poderiam ter.

Além disso, tentamos não tornar esta atividade obrigatória, sempre deixando ao aluno a opção de querer ou não jogar (tanto é que alguns alunos não quiseram jogar). Pois de acordo com Borin (2002), o jogo é uma das muitas alternativas para o ensino da matemática, e não a única, portanto não deve ser obrigatória.

Dentre as contribuições dos jogos, observamos que estes foram viáveis para que os alunos aprendessem a trabalhar em grupo, conforme o registro ${ }^{6}$ de Katiane.

Nesse semestre eu gostei das aulas de matemática, achei criativas, nunca pensei que eu pudesse aprender matemática brincando, gostei de todos os jogos, achei mais fácil aprender com os jogos porque fazemos grupos

\footnotetext{
${ }^{6}$ Relatos dos alunos transcritos de forma original sem nenhuma correção ortográfica.
} 
Durante a realização do jogo, tivemos muito barulho, mas isso é explicado por Borin que afirma que o barulho nessa situação é inevitável, por causa das discussões para se chegar aos resultados e também porque os alunos podem não ter o hábito de trabalhar em grupo (é o que ocorreu com esta turma). Um fato interessante durante os jogos foi que os alunos mais agitados durante a aula eram os mais motivados nos jogos.

É interessante verificar que existem alunos que gostam de jogos, e também os que não gostam desta atividade. Alves (2001) justifica o fato de alguns alunos não gostarem do jogo porque já estão acostumados a estudar matemática da forma tradicional. Isso pode ser comprovado na redação de Leonardo.

Sobre as áreas das figuras geométricas, eu entendi tudo, sei as fórmulas de todas as figuras; eu entendi melhor porque eu já sabia um pouco e agora eu sei todas.

Os volumes dos sólidos geométricos, não sei quase nada, não prestei atenção nas aulas e também porque é bem mais difícil que os outros conteúdos.

Sobre o perímetro e a área do círculo eu entendi bem, as fórmulas alguns desenhos que são complicados.

Os jogos não fez diferença para que eu entendesse melhor, ficou na mesma.

Da mesma forma, Vinicius, apesar de participar dos jogos, expôs o seguinte comentário a respeito de sua aprendizagem durante esta atividade:

... e sobre os jogos para mim não resolveram nada, apenas passou o tempo.

Mesmo assim pudemos perceber que a maioria dos alunos gostou dos jogos e que os mesmos ajudaram na compreensão do conteúdo estudado, como pode ser constatado nas redações de Patrícia e Lorraine.

Fizemos vários exercícios que nos ajudaram a entender melhor e além de tudo jogos como o da memória que o meu grupo ganhou e o corrida que também ganhamos, eu gostei mais da corrida que estava com algumas dúvidas sobre perímetro e área, mas agora entendi e tomara que eu tire uma nota boa.

Eu não estava entendendo muito bem o perímetro e a área do círculo, mas hoje fizemos um jogo de corrida que ajudou a compreender essa matéria e eu acertei todas. 
itinerarius

Peflectionis
Revista Eletrônica de Educação do Curso de Pedagogia do Campus Avançado de Jataí da Universidade Federal de Goiás [Vol I - n.2 ] [jan/jul] [ 2006 ]

Em especial a aluna Luana acrescenta que estas atividades com jogos foram essenciais na sua aprendizagem.

Eu achei muito legal o jogo da memória e o jogo de corrida, que ajudou bastante a fixar bem todas as matérias desde o início, porque ajudou a aprendermos bem várias fórmulas. Achei muito bom ter estudado de uma forma diferente e ter entendido as matérias.

A partir desse relato, pudemos concluir que a maioria dos alunos, através das atividades propostas com jogos, conseguiu assimilar a matéria estudada o que também facilitou nas demais atividades desenvolvidas durante as aulas.

\section{Resultados Alcançados}

Ao educador as responsabilidades vão além de reproduzir o passado e o presente, cabe a ele preocupar-se em construir um futuro e um futuro diferente que seja melhor que o hoje. Para que a educação venha a atender essas expectativas, surgem novas metodologias que tem como objetivo tornar o ensino mais eficaz e um aprendizado consideravelmente mais atraente.

De acordo com Brasil (1998), é papel da escola desenvolver uma educação que coloque o aluno ante aos desafios que lhe permitam desenvolver atitudes de responsabilidade, compromisso, crítica, satisfação e reconhecimento de seus direitos e deveres. Nesse aspecto, a Matemática pode dar sua contribuição, ao desenvolver metodologias que enfatizem a criatividade, a iniciativa pessoal, o trabalho coletivo e a autonomia advinda da confiança na própria capacidade para enfrentar desafios.

Pensando nisso e em outras idéias já referidas, desenvolvemos atividades lúdicas, a saber: papel quadriculado, geoplano, material dourado, recortes de cartolina e jogos de treinamento. E através destas atividades buscamos tornar a matemática algo simples e acessível a todo e qualquer aluno, e ainda tornar as aulas mais interessantes, prazerosas e que ao mesmo tempo sejam capazes de levar o aluno a construir conhecimento, proporcionandolhe uma aprendizagem significativa.

Acreditamos que conseguimos fazer com que a maioria dos alunos entendesse a dedução das fórmulas sem precisar decorá-las (através de papel quadriculado, geoplano, recortes de cartolina), pois sempre salientávamos que uma figura da qual aparentemente não sabíamos calcular a área podia ser decomposta em outras figuras cuja área era conhecida ou então sobrepostas, entre outras. E como já descrito anteriormente, a resolução da aluna P.B 
representa bem a idéia de manipulação de uma figura, em que primeiro sobrepôs as partes iguais e depois juntou as duas restantes sobrepondo na terceira parte, chegando a área de um retângulo, além do mais nem mesmo nós pensamos assim ao resolvermos essa questão (resolvida antes da aula).

Um fato até engraçado sobre manipulação de figuras é que muitas vezes não era possível sobrepor as partes para chegar à área desejada, mas alguns alunos sem ter observado bem a figura queriam fazer esse processo. Quando isso acontecia sempre fazíamos questionamentos, com o intuito de mostrá-los que naquele caso não era possível sobrepor.

E como já foi comentado anteriormente, essas atividades tornam as aulas dinâmicas e prazerosas, desenvolvendo no aluno atitudes como curiosidade, desejo, criatividade, entre outras. Constatamos nas aulas com geoplano algumas atitudes, entre elas, a criatividade dos alunos que pode ser vista nas fotos abaixo.

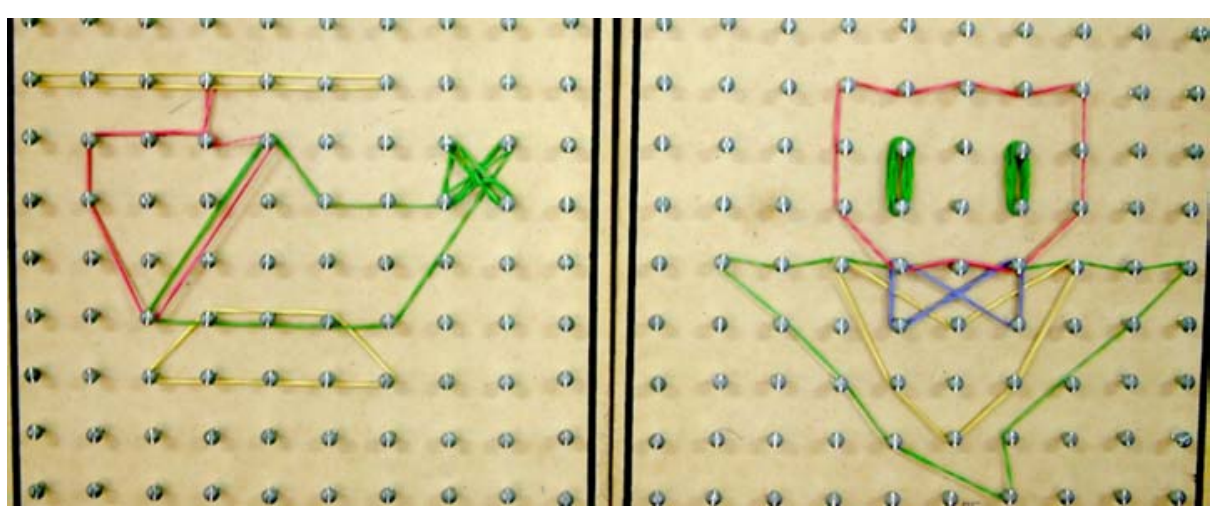

Figura 03 - Desenhos criados pelos alunos

Com relação aos jogos de treinamento sempre tomamos alguns cuidados como não torná-los obrigatórios, ambos tinham regras e envolviam dois ou mais alunos e estudamos os dois antes de aplicá-los, o que propiciou um ambiente gratificante e atraente. E principalmente para aqueles alunos considerados mais inibidos, constatamos que o jogo contribuiu para a formação de atitudes, através do desafio que o próprio jogo carrega, despertando interesse, autoconfiança, iniciativa, além disso, favoreceu a socialização dos alunos e incentivou o trabalho em equipe. Todos esses aspectos confirmam as teorias já expostas.

Tivemos também algumas limitações como barulho e desinteresse por parte de alguns alunos, que alegaram que o jogo não ajudou em nada. Alves (2001) explica essas duas 
reações; a primeira, que é causado pelo entusiasmo produzido pelo jogo e o outro seria porque alguns alunos já estão acostumados a estudar matemática de modo tradicional.

Outra limitação constatada foi em duas aulas expositivas, as quais realizamos em grupos (2 a 3 alunos). Nosso objetivo nessas aulas era que os alunos primeiro realizassem a tarefa em grupo, e ainda em grupo, após terem concluído, interviríamos (confirmando a conclusão a que teriam chegado), mas o barulho gerado nos grupos dificultou tanto nossa finalização, quanto a compreensão dos alunos.

Mas apesar dessas limitações, através do jogo, atingimos mais um objetivo que era fixar os conteúdos estudados - característica do jogo de treinamento. E, conseqüentemente atingidos esses dois objetivos motivamos os alunos a uma nova aprendizagem. Isso pode ser constatado em algumas redações, entre elas, a de Amanda e Rogério.

\section{Matemática diferente}

Nesse simestre as aulas de Matemática foram diferentes tivemos duas estagiarias que com seu potencial nos fizeram ver e aprender a matéria de forma divertida e diferente.

Além de tudo, tivemos o auxilio de jogos, que fizeram com que nós ficássemos dedicados e entusiasmados com a nova maneira de aprender. Relembramos também as formas geométricas, os volumes de sólidos geométricos, área do círculo e perímetro, e estes nos fizeram trabalhar com materiais diferentes, como: o material dourado, recortes de cartolina, geoplano, etc.

Com o ocorrer destes, vejo que apesar de Matemática ser uma matéria complicada, podemos usar meios diferentes para que não fique chato e nem enjoativo, para que com isso possamos desfrutar de seus bens e praticá-los.

Em particular pudemos verificar que o aluno Rogério apresentou melhoras com relação ao seu rendimento, visto que antes de nossa aplicação este aluno era desinteressado e agitado e, logo após as primeiras aulas, essas atitudes foram transformadas em outras, que ele mesmo descreve em sua redação.

\section{Professoras eu não sabia que vocês iam me animar desse tanto.}

No começo eu achei que vocês eram chatas, que eu não ia entender nada, mais fui gostando cada vez mais da sua suas aulas, fui participando das aulas, a primeira vez que eu participei foi a aula que teve medidas de comprimento, foi legal aprendi fazer de várias maneiras as medidas mais sabia de um jeito mais fácil que era colocando a vírgula e acrescentar o zero, achei mais dificil a maneira da regra de três.

Teve também de massas de kilo etc. Essa foi a aula que eu participei a primeira vez na sua aula.

A segunda aula eu não sei mais teve a aula de figuras geométricas que foi o próximo conteúdo, que eu comecei a ter dificuldade para não lembrar das fórmulas mas fui entendendo por causa da aulas e 
gincanas que teve, que foi muito divertido que foi o (jogo da memória e o jogo da corrida)

Eles me ajudaram a compreender essa matéria.

O próximo conteúdo foi perímetro e área do círculo, que foi complicado, não sabia no começo qual era a fórmula do perímetro e a fórmula da área, mas compreendi nas nas aulas que teve a gincanas e as várias explicações de vocês, simplesmente não tive muita dificuldade, mas eu tirei minhas dúvidas com vocês.

Constatamos também no decorrer das aulas o avanço da aluna Katiane que, antes da aplicação de nossa proposta, tinha muitas dificuldades, e, além disso, era desmotivada. Já em nossa proposta ela tornou-se participativa e motivada com relação às aulas, isto porque diferentemente da professora titular, preocupávamos com o aprendizado de "todos" os alunos, questionando-os durante as aulas, se estavam entendendo o conteúdo. Em especial esta aluna tinha um grande interesse e tirava dúvidas até mesmo fora do horário de aula. Na última atividade de sala seu desempenho foi ótimo, pudemos perceber que ela não tinha tantas dificuldades como antes.

Estas atitudes descritas acima mostram a motivação dos alunos com relação a uma nova aprendizagem, conseqüência dos dois primeiros objetivos que tínhamos traçado no início da elaboração desta proposta.

E desta forma através de nossa prática pedagógica buscamos uma nova sala de aula onde valoriza-se o aluno, sua realidade, suas inteligências múltiplas, suas concepções prévias, atendendo a um novo cenário educacional, recriando novas formas de aprender.

Referências Bibliográficas:

ALVES, Eva Maria S. A ludicidade e o ensino da matemática: uma prática possível. Campinas: Papirus, 2001.

ARAÚJO, Iracema Rezende de Oliveira. A utilização de lúdicos para auxiliar a aprendizagem e desmistificar o ensino da matemática. 2000. 136f. Dissertação (Mestrado em Engenharia de Produção) - Programa de Pós-Graduação em Engenharia de Produção, Universidade Federal de Santa Catarina, Florianópolis, 2000.

BORIN, Julia. Jogos e resolução de problemas: uma estratégia para as aulas de matemática. 4.ed. São Paulo: Caem-IME/USP, 2002.

BRASIL. Secretaria de Educação Fundamental. Parâmetros Curriculares Nacionais: Matemática. Brasília: MEC, 1998. 
Revista Eletrônica de Educação do Curso de Pedagogia do Campus Avançado de Jataí da Universidade Federal de Goiás [Vol I - n.2 ] [jan/jul] [ 2006 ]

ISSN: $1807-9342$

LIBÂNEO, José Carlos. Organização e gestão da escola: teoria e prática. 4. ed. Goiânia: Alternativa, 2001 